\title{
An Analysis on the Hindrances of the Implementation of the CTG Switching Policies in Rural Areas in Hebei Province: A Smith Policy-Implementing-Process Framework
}

\author{
Yishu Ren \\ Department of Political Science, University College London, London, UK \\ Email: rysh0114@163.com
}

How to cite this paper: Ren, Y. S. (2020). An Analysis on the Hindrances of the Implementation of the CTG Switching Policies in Rural Areas in Hebei Province: A Smith Policy-Implementing-Process Framework. Open Journal of Social Sciences, 8, 14-28.

https://doi.org/10.4236/jss.2020.88002

Received: July 13, 2020

Accepted: August 3, 2020

Published: August 6, 2020

Copyright $\odot 2020$ by author(s) and Scientific Research Publishing Inc. This work is licensed under the Creative Commons Attribution International License (CC BY 4.0).

http://creativecommons.org/licenses/by/4.0/

\begin{abstract}
To improve the air quality, Chinese governments issued a series of policies to carry out the coal-to-gas (CTG) transition. However, the implementation of CTG switching policies has been hindered in practice, which has caused a lot of negative effects. Therefore, this essay aims to analyze the hindrances of the implementation of CTG switching policies in rural areas in Hebei province by using Qingzhou Town as a case, employing interviews on officials from implementing organizations and the questionnaire survey method for rural residents. The Smith Policy-Implementing-Process Framework (the Smith model) was used as the theoretical framework to provide a complete analysis of policy implementation hindrances regarding idealized policy, implementing organization, target group, and environmental factors. According to the survey results, there were 10 main hindrances including the problem with policy design, such as simplified policy goal and one-size-fits-all problem; the lack of flexibility, excessive implementation by the implementing organization; target group's weak environmental awareness, insufficient economic incentives, and low level of participation and policy understanding; several environmental factors, such as the imperfect supervision and performance evaluation mechanism, the ineffective market mechanism, limited gas resource channels, and insufficient infrastructure.
\end{abstract}

\section{Keywords}

Coal-to-Gas, Policy Implementation, Hindrances, The Smith

Policy-Implementing-Process Framework 


\section{Introduction}

Currently, a natural gas revolution is taking place worldwide. The regional atmospheric environmental problems of pollutants characterized by fine particles (PM2.5) are very serious in China. Therefore, to improve the air quality, a coal-to-gas (CTG) transition is carried out by the Chinese government. The CTG transition refers to using natural gas (including conventional and unconventional natural gas, etc.) to replace low-energy utilization and high pollutant emissions of coal-fired coal in residential and industrial production (State Council, 2013). However, the implementation of policies has been hindered in practice, which has caused a series of negative effects.

This essay aims to answer the question that what are the hindrances of the implementation of the coal-to-gas switching policies in rural areas in Hebei province. The answer to this question is key to foster the implementation of CTG switching policies. To complete the current research, hindrances and the reasons behind them are supposed to be explored, and empirical evidence is supposed to be provided.

This essay is against this background, taking Qingzhou Town as a case, through interviews and questionnaire surveys to explore the hindrances of the implementation of the CTG switching policies in Hebei province, based on the Smith Policy-Implementing-Process Framework.

This paper was organized as follows: Section 2 reviewed existing literature to find out the gaps and make it clearer how this paper fills these gaps. The theoretical framework was also introduced in this section. Section 3 discussed the research design and the reasons for making this design. Section 4 conducted the research study, shown in the results. Section 5 discussed the results on the basis of the Smith Policy-Implementing-Process Framework. The final section summarized findings, and contributions, and made suggestions for further studies.

\section{Literature Review and Theoretical Model}

\subsection{Literature Review}

Since the 1990s, studies focused on the factors influencing CTG enforcement and highlighted the role of economic factors and environmental constraints, such as investment, high cost of gas production, and the price mechanism in shaping Chinese energy development (Lin, 1998). After the 2000s, several national circumstances including urbanization, a rapidly growing population, and industrialization were considered in energy development (Ren, Zeng, \& Zhou, 2004). In recent ten years, insufficient storage of natural gas, constrained access to natural gas infrastructure, and methane leakage from the natural gas industry have been paid more attention (Minchener, 2011; Qin et al., 2017). Besides, political considerations were also included in the mechanism for influential factors, such as energy security issues, and governments' strict control over unreasonable distribution (The Oxford Institute for Energy Studies, 2017). In addition, a study in 2019 explored whether and how individuals cooperate with the implementa- 
tion of CTG switching policies depends on their beliefs about others' beliefs or "second-order beliefs" (Schuldt et al., 2019). They conducted face-to-face interviews with a socioeconomically diverse sample, and concluded that second-order beliefs, especially those regarding proximal reference groups strongly predicted individuals' policy support.

Furthermore, several research studies focus on the effects of CTG transition. Industrial efficiency of coal and natural gas were compared (Hu et al., 2010). It was concluded that after the transition, boilers and industrial resources were more effectively controlled. And in the recent 5 years, life-cycle comparison of water consumption and greenhouse gas emissions between coal and gas were made (Chang et al., 2015). It was concluded that this transition is a good opportunity to deliver climate benefits with proper methane leakage control (Qin et al., 2018). The life cycle assessment and life cycle cost methods were also applied to compare the environmental impact and economic cost of household energy usage before and after the CTG transition, and concluded that the environmental impact of energy consumption for rural households in northern China will be reduced by $50 \%-60 \%$, while the economic cost will increase in $2000 \mathrm{RMB}$ per year (Li et al., 2020). Another study presented a quantitative assessment of the water footprint for Chinese CTG industries and proved that large-scale development of CTG projects would present significant risks to local water resources (Wang et al., 2019a). In addition, through the evaluation of the CTG transition's effects on economic activities, prices, and consumption, the assumption about growth rates in electricity generation from renewables is identified as the key determinant (Arora, Caibc, \& Jones, 2016).

In general, existing literature on China's CTG transition focuses on the factors influencing its enforcement, and its impacts. Although potential challenges have been identified, there is a lack of empirical evidence on hindrances of the implementation of CTG switching policies. Moreover, the influential factors identified in previous studies (Lin, 1998; Minchener, 2011; Schuldt et al., 2019) mainly regard the policy environment issues; nevertheless, hindrances being caused by the policy content and the policy executors are ignored. There is a need for a more systematic and complete study on hindrances of policy implementation. Furthermore, most studies took the policy implementation in the whole China range as the research object, deeper factors and specific characteristics are required to be explored. Therefore, this essay analyzed the hindrances of the implementation of CTG switching policies systematically, based on the Smith Policy-Process-Implementing Framework to include more factors, such as the target group issue, the policy content issue. The policy implementation in Hebei rural area is selected as a case to provide a deep and detailed analysis, and survey methods are employed to provide empirical evidence.

\subsection{Theoretical Model}

At the end of the 1970s, scholars started to establish theoretical models based on individual case studies for analyzing the process of policy implementation. T.B. 
Smith was one of the earliest scholars to build models for the policy implementation process (the Smith model). He suggested that there are four important components in the policy implementation process. The first one is the idealized policy which is relevant to the form, type, program, and images of the policy. Second, the implementing organization works as the implementing subject, among which there are three key factors including the structure and personnel, the leadership of the administrative organization, and the implementing program and capacity. Third, the target group is defined as those who are required to adapt to new patterns of interaction by the policy. And the final one is the environmental factors which refer to those factors influencing or being influenced by the policy implementation. The interaction between these components produces tensions, affecting the effects of policy implementation, and fostering or hindering the effects of policies through feedbacks (Smith, 1973) (Figure 1).

As the classic policy implementation model, each component in the Smith model is quite typical. And these are two situations that are suitable to apply this mode: the internal factors in the policy implementing process will influence a lot to the effect of implementation; the policy is implemented from top to bottom. CTG switching policies belongs to these two situations, since superior governments set tasks, subordinate administrative staffs finish these tasks, during which various factors affecting the implementing effects. Therefore, the Smith model is chosen as the theoretical model.

Previous studies applying this theoretical model to analyze the hindrances of policy implementation from the perspective of powers and interests (Wang, 1998), study the restraining factors and path choice (Jiang, 2017), simply research the policy implementation process (Deng \& Xu, 2012; Huang, 2018). Compared with existing literature using the Smith model, this essay not only analyzes the hindrances of the policy implementation, but also explores the deep reasons behind these hindrances.

\section{Methodology}

This essay selected the implementation of CTG switching policies in Qingzhou Town which is a rural area in Hebei province as an individual case, so that in-depth and detailed surveys can be conducted, specific characteristics can be considered. Hebei province was chosen since it is the province with the most serious air pollution, and the province where CTG switching policies are being implemented most rapidly. And for selecting Qingzhou Town, there were two reasons. First, the coal-to-gas switching policies were implemented in Qingzhou town since July 2017; therefore, compared with the policy implemented in other towns, it is more continuous and complete in Qingzhou town. In addition, considering data accessibility, Qingzhou town is my hometown; thus, it is more convenient to conduct surveys and collect primary data here. When analyzing the results, public documents such as public communication, original policy documents, media articles are combined with primary data I gained, to give a more clear and deep discussion. 


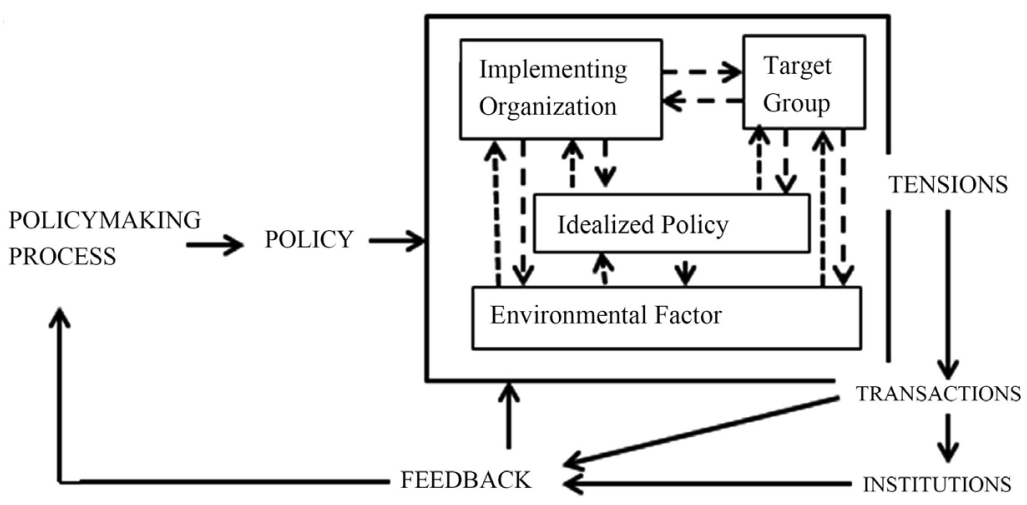

Figure 1. The Smith Policy-Implementing-Process Framework.

To collect primary data, two survey research methods were employed. One is the questionnaire survey which was used to ask structural questions and gather a large number of information in a short period of time. During October to November 2019, 100 questionnaires were allocated to rural residents living in Qingzhou Town, and finally obtained 98 available ones. It is a quite high responding rate of $98 \%$ because the survey was carried by face to face interviewing to the respondents. 5 Villages in Qingzhou Town were selected by using the convenience sampling method, including Li Jia Zhen, Liu Que Tun, Geng Guan Tuan, Ba Li Zhuang, and Xi Jie. And 20 families were surveyed in each village. And considering the household income may affect respondents' attitudes on the CTG switching policies, to ensure the representativeness of samples, using the stratified sampling method, the respondents with different levels of annual income were selected according to their proportion. Finally, there were 16 families with an annual income under 5000 yuan, 22 families with income between 5000 and 10,000, 38 families between 10,000 to 20,000, and 22 with annual income more than 20,000. The questionnaire included three parts. The first part mainly asked about the basic situation of the respondent's family. The second part aimed to learn about the participation of the respondent in the CTG policies. And the third part focused on the level of respondents' satisfaction with the implementation of CTG policies and reasons. The content of the questionnaire has been translated in Appendix.

Furthermore, to ensure greater depth for the research, phone interviews were conducted as a complementary. The questionnaires were distributed to rural residents, that are, the target group for policy implementation. However, according to the Smith model, the policy design, implementing organization, and environmental factors are also very significant. Therefore, questions regarding these three aspects are also required to be asked to gain more complete information. In the Qingzhou town government, different departments are responsible for different functions. The Development and Reform Commission and Energy Department are the two departments mainly leading CTG transition. Therefore, I conducted phone interviews on the directors of these two departments. Furthermore, to learn more information from practical implementation, a Village 
Committee Director was also included in the interview. Moreover, to overcome the limitation of options in the questionnaire, 2 rural residents in Qingzhou Town were interviewed via in-depth semi-structured phone interviews, between November and December 2019. While each interview broadly followed the list of interview questions, the semi-structured nature allowed for flexibility to reveal specific issues in greater detail and can enable interviewees to uncover unanticipated information and novel insights. Information acquired from interviews was cross-checked with our results from questionnaires and public documents.

\section{Results}

\subsection{Results of the Questionnaire Survey}

The results of the questionnaire survey are listed (Table 1).

According to the results, respondents have a low-level participation of the CTG switching policies. First, their understanding of the CTG policies was insufficient. $13.40 \%$ of the respondents indicated that they almost knew nothing about the CTG policies; $50.52 \%$ of the respondents claimed that they "know a little". Moreover, the channels through which they gain information about CTG switching policies were limited. Relatives and friends, mass media, and village cadre visits were the three main channels for obtaining information. Only 25 people learned about the policy through policy briefings. Since most channels were not official and formal, the accuracy of information gained from these channels was relatively low. Furthermore, the respondents' environmental awareness was weak. $48.98 \%$ of the respondents indicated that "it is not necessary and has no obvious effect on environmental improvement"; another $16.33 \%$ of the respondents said not very clear, nor care about its impact on the environment.

From the results, it can be known that the degree of satisfaction of respondents to the CTG switching policies was not high, and the economic considerations and the rigid implementing method were the main factors affecting their satisfaction. The proportion of respondents with a satisfaction level of average and below was about $64.28 \% .54 .08 \%$ of respondents selected heating costs as the most important factor affecting their degree of satisfaction. The heating subsidies were also concerned by $46.79 \%$ of respondents. From the basic information about respondents' families, the heating costs were high. $65.30 \%$ of respondents spent more than 2000 yuan. However, $77.55 \%$ of households received subsidies even less than 200 yuan. Regarding the methods and attitudes of enforcing staffs, $60.20 \%$ of interviewees believed that "the means of execution are appropriate, but the methods lack flexibility"; followed by "appropriate means of enforcement, but mechanical and single" taking up for $33.67 \%$.

\subsection{Results of the Interview}

Interview responses were transcribed from the interviewer's notes and mobile recording (Table 2). 
Table 1. The results of the questionnaire survey.

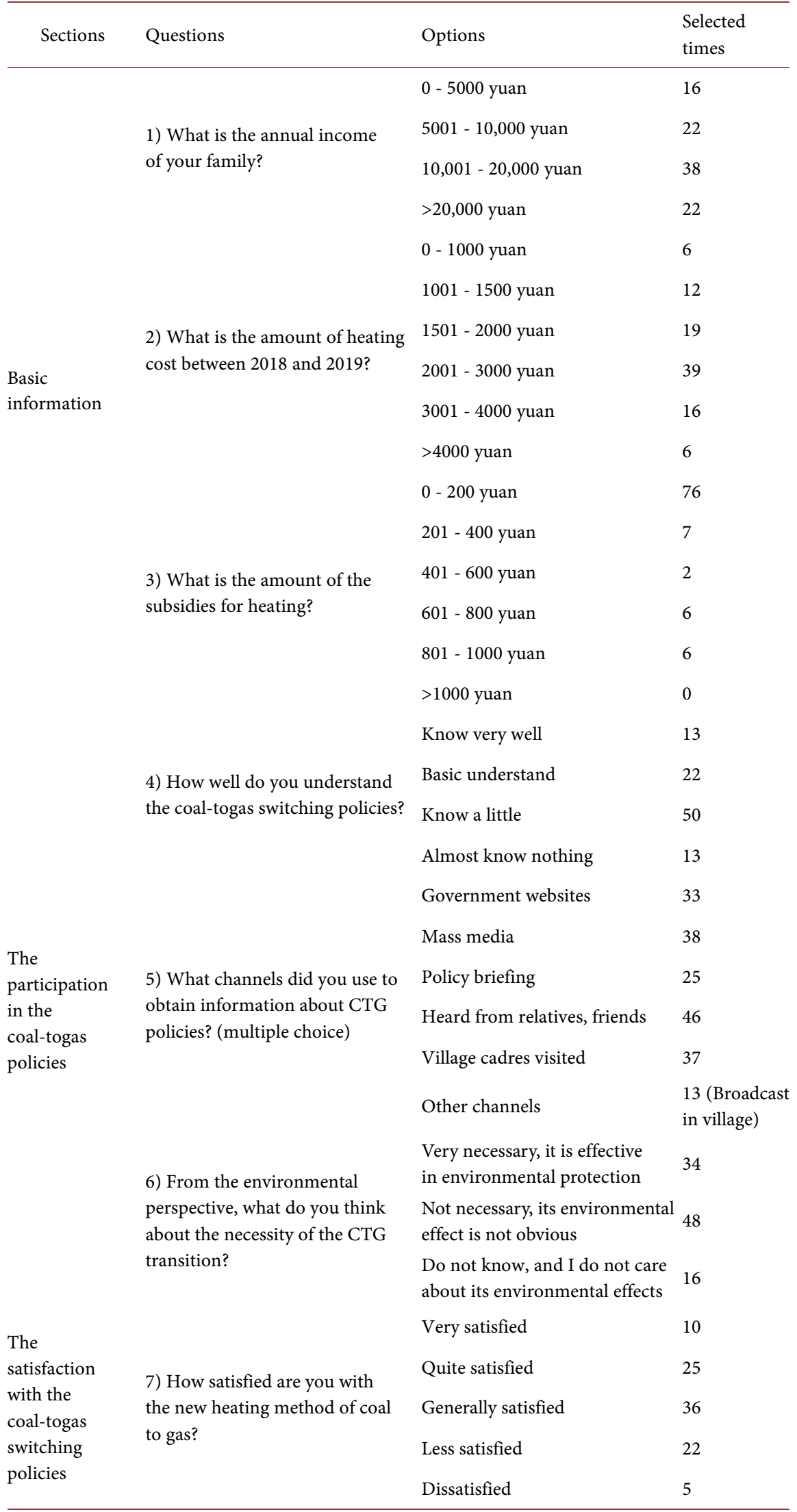




\section{Continued}

8) What are the factors affecting your satisfaction? (Multiple choice)

9) What do you think about the methods and attitudes of enforcing staffs?
The change in heating cost after transition

The amounts of subsidies for heating

More convenient after transition

The change in indoor temperature

The security of the facilities 54

Others

Enforced by compulsory means with bad attitude

Appropriate means of enforcement, but Mechanical and single

Enforce with flexibility, fully respecting users' wishes and rights

Table 2. The results of interviews.

\begin{tabular}{|c|c|c|c|}
\hline Interviewee & Number & Question & Response \\
\hline $\begin{array}{l}\text { The director of } \\
\text { the Development } \\
\text { and Reform } \\
\text { Commission in } \\
\text { Qingzhou Town. }\end{array}$ & D1 & $\begin{array}{l}\text { What do you think } \\
\text { is the problem in the } \\
\text { design of Hebei's } \\
\text { CTG switching } \\
\text { policies? }\end{array}$ & $\begin{array}{l}\text { "First of all, the policy goal of CTG conversion } \\
\text { is simply understood as increasing the share of } \\
\text { renewable energy. For example, 'a net } \\
\text { reduction of } 40 \text { million tons from } 2012 \text { to } \\
2017 \text { in the coal consumption' is one of the } \\
\text { goals of the Hebei Province Air Pollution } \\
\text { Prevention Action Plan Implementation Plan } \\
\text { as one of the specific targets. Secondly, the } \\
\text { policy has a one-size-fits-all problem. Hebei } \\
\text { Province claimed that within three years, the } \\
\text { urban-rural bulk coal replacement in the } \\
\text { whole province will be basically achieved. } \\
\text { However, some adobe houses are still reserved } \\
\text { in the rural areas of Hebei Province, making it } \\
\text { difficult to carry out pipeline } \\
\text { transformation." }\end{array}$ \\
\hline & D2 & $\begin{array}{l}\text { What do you think } \\
\text { is the main problem } \\
\text { with the } \\
\text { implementation of } \\
\text { CTG switching } \\
\text { policies? }\end{array}$ & $\begin{array}{l}\text { "I think the main problem is the excessive } \\
\text { execution led by the campaign-style } \\
\text { implementation. The instructions are passed } \\
\text { level by level under the bureaucracy. Each } \\
\text { level of government increases the number of } \\
\text { tasks to ensure to gain the winner in the } \\
\text { competition with other governments at the } \\
\text { same level." }\end{array}$ \\
\hline
\end{tabular}


The director of the Energy Department in Qingzhou Town Government

A village committee director
What is the main financial source for the clean energy development?
"So far, the development of clean energy mainly relies on government funds, because we have not mastered the core technology and has not formed an industrial scale, and the investment risk is relatively high. Venture capital institutions and commercial banks and other investment institutions are prohibitive. Without the support of funds, the technology is difficult to progress, so clean energy financing fall into a vicious circle."

"From the upstream of the natural gas in the Beijing-Tianjin-Hebei region, long-distance gas pipelines such as the West-East Gas Pipeline of the CNPC system and the Shaanxi-Beijing First, Second, and Third Lines are the main supply systems. The final Whether the supply gas source is the gas fields of Xinjiang and of the natural gas for northern Shaanxi and Central Asian the CTG transition is countries, and LNG imported from Tianjin sufficient? and Tangshan by sea. Since November 28, 2017, the province's natural gas supply has entered an orange warning, and the supply and demand gap has reached $10 \%-20 \%$. Local governments are required to limit gas and stop gas for industrial and commercial users to ensure civil natural gas supply."

"In practice, we just implemented the policy, Whether there is and there is not any change being made any flexibility during during implementation. Although there are the implementation residents reflecting their needs through of the CTG switching telephone, for example, some poor households policies? cannot afford the cost of CTG, but there has not been any response."

"The safety supervision bureau was mainly responsible for monitoring and evaluating the quality of the CTG switching projects, and the township government supervised the

Was there any supervision on the implementation of CTG switching implementation progress of the project. The financial department will conduct a performance evaluation of the funds invested policies? in each project, the amount of natural gas used, and the reduction of coal consumption. But obviously, the current performance evaluation mechanism is not in place."

According to the six questions and their responses, there were six main hindrances of the implementation of the CTG switching policies. First, about the policy design, the understanding of the policy objective seems to be over-simplified, and there seems to be a one-size-fits-all problem. Second, regarding the imple- 
menting organization, there were two hindrances including excessive implementation and the lack of flexibility. Third, there were three hindrances caused by economic, political, and energy factors respectively. The development of clean energy in China still highly relies on government funds due to the lack of a well-constructed market mechanism. The supply of natural gas is insufficient because of limited channels. Besides, current performance evaluation mechanism on implementing organization has not been in place.

\section{Discussion}

\subsection{Hindrances Caused by the Policy Design}

According to the interview D1, there were two main problems with the design of CTG policies. First, the policy objective has a tendency of simplifying the concept of the energy transition. It can be seen that a number of policies related to CTG transition have the main goals of reducing coal shares and increasing natural gas shares (Zhu, 2015). This single quantitative goal has led to problems such as the ignorance of facility safety, reconstruction costs, and target group satisfaction during policy implementation.

Moreover, there is a one-size-fits-all problem in policy design, while ignoring different conditions across various areas. For example, rural houses do not have the conditions for pipeline renovation. Residents are supposed to be given more freedom to choose (Wang et al., 2019b). Besides, the practice of Beijing Guohua and Huaneng Thermal Power Plants has proved that through online monitoring, large-scale coal-fired thermal power plants can meet the basic requirements for environmental protection. Due to the problem of insufficient natural gas supply, natural gas cogeneration technology is not suitable as the main heat supply source plant. Therefore, it seems unreasonable to use natural gas to replace coal as the main heating method in all regions of the country at this stage.

\subsection{Hindrances Caused by the Implementing Organization}

From the results of the questionnaire survey and interviews, it can be known that implementing organizations lack flexibility. The result of the final question in the questionnaire shows that $60.20 \%$ of respondents suggested that although the means of implementation are appropriate, the methods lack flexibility. According to the interview V1, even if some villagers have made suggestions, the implementing organization basically did not make any adjustments or respond, since they only are responsible to the higher authorities.

In addition to the lack of flexibility, excessive implementation is another problem existing in the implementing organization of CTG transition (Interview D2). In the Chinese-style authoritarian political system of the party-state, the competitive selection is the main way to produce local officials, thus, promotion is the most important political incentive for local cadres. Although environmental protection has been used as hard indicators and incorporated into the local cadre assessment indicator system by local governments. However, these quan- 
titative indicators have many obstacles in the process of conversion into specific environmental effects. First, some local governments often sacrifice other environmental indicators to meet the requirements of priority indicators. Second, the pressure transmission under the bureaucratic system has resulted in too much pressure when the instructions come to the bottom level of governments, which may lead them to pay too much attention to data, while ignored the real effects (Ran, 2013).

\subsection{Hindrances Caused by the Target Group}

The environmental awareness of the target group is relatively weak, which is also one of the factors hindering the implementation of the CTG policies. The results of the questionnaire indicated that most of the respondents believe CTG projects have little effect on environmental protection or do not care about their environmental impacts. This might be because the educational level of rural residents in China was generally low (Xu \& Ge, 2020). Their low environmental awareness made them have few incentives to cooperate with CTG policies which are a series of policies that may sacrifice other conditions to protect the environment.

In addition to the weak environmental awareness, the lack of economic incentives due to low subsidies is another important reason for the low willingness of the target group to cooperate. According to the result of the questionnaire survey, $77.55 \%$ of respondents received less than 200 yuan subsidies. And through the comparison between the amounts of heating costs and subsidies, it can be observed that for most households, the amounts of subsidies accounts for less than one-tenth of the heating costs. However, the answers to the question that what are the factors affecting your satisfaction illustrated that the change in heating cost and the amounts of subsidies are two important factors ranking in the second and third positions. Therefore, the high heating costs reduced the target group's incentives.

Moreover, according to the results of the fifth and sixth questions in the questionnaire, the target group's knowledge and participation in CTG policies are obviously insufficient. Most of the respondents to the questionnaire survey did not even have a basic level of knowledge of CTG transition. Besides, most rural residents learned about these policies through relatives and friends, which may lead to information distortion. Besides, interview V1 indicated that suggestions made by the target group did not been adopted, which is another reason for low-level participation of the target group.

\subsection{Hindrances Caused by Environmental Factors}

The implementation of any policy will inevitably interact with certain social factors and will be affected and restricted by the social environment (Ning, 2011). To some degree, incomplete political, financial, and infrastructure environments constrain the development of CTG transition. First, there is a lack of effective 
supervision and performance evaluation mechanism of the implementation of CTG transition. Based on interview V2, the supervision is limited to the performance of gas companies; there is no agency to supervise the governments' behavior. Besides, the evaluation criteria merely pay attention to quantitative tasks, but ignore the satisfaction of the target group, lacking the attention on the connection between the policy, the target group and the policy environment. And this performance evaluation mechanism merely focuses on evaluating the results of policy implementation, instead of identifying deficiencies in policy implementation.

Furthermore, the interview D3 illustrated that there has not been an effective market mechanism for clean energy development in China. Subsidies for the development of natural gas and the development of clean energy in China mainly rely on the government. An effective investment and financing mechanism to promote the development of clean energy has not yet been established. The main reasons are low added value, backward technology, high investment risk, and the profit-seeking nature of investment institutions. In addition to this, the difficulty of financing commercial banks is another reason. Although the government strongly supports the development of the clean energy industry and encourages banks to relax credit policies, overcapacity has increased commercial banks' concerns about clean energy investment (Hu \& Zhang, 2013).

Last but not least, limited gas resource channels, the insufficient infrastructure of gas storage and transportation are the direct reasons leading to gas shortage. From the interview E1, it can be known that the gas source channels in Hebei Province are limited, and not stable enough. After entering the winter in the past two years, the countries along the Central Asian that are the final source of Hebei's natural gas pipeline intercepted part of the gas supply to China, so the imported natural gas was reduced. However, due to the pay-as-you-go agreement, China cannot restrain this kind of behavior; at the same time, when the gas source is in short supply, the output of the liquid plant also needs to supplement the pipeline usage, and the LNG output of the liquid plant drops (Huang, 2018). Besides, the insufficient interconnection of the pipeline network and insufficient gas storage and peak shaving facilities also constrain CTG transition.

\section{Conclusion}

This essay found out that there were 10 main hindrances based on the Smith model by using the interview and questionnaire survey methods, including the problems with policy design, such as simplified policy goal and one-size-fits-all; the lack of flexibility and excessive implementation by the implementing organization; target group's weak environmental awareness, insufficient economic incentives, low level of participation and policy understanding; several environmental factors, such as the imperfect supervision and performance evaluation mechanism, the ineffective market mechanism, limited gas resource channels and insufficient infrastructure. 
This essay has three main contributions to the study of China's CTG transition. First, this essay provided empirical evidence on the hindrances of the implementation of CTG policies. Second, based on the Smith model, this essay identified a more complete mechanism for hindrances regarding policy design, implementing organization, target group, and environmental factors. Moreover, through an individual case study, deeper factors and specific characteristics can be explored. Furthermore, not only hindrances of the implementation were identified, reasons behind these hindrances were also analyzed.

There were still several limitations in this essay. For example, the exploration of the interactive relationship between the four impact factors of the Smith model is not deep enough. Moreover, the research scope is relatively narrow. The sample size is not large enough. Furthers studies will continue to analyze the factors hindering the implementation of CTG switching policies, dig deeper into the institutional factors behind the implementation of chaos, and conduct a wider range of surveys and sampling.

\section{Acknowledgements}

I would thank my supervisor Dr. Peter Warren and Professor Qunfang Wu for their guidance. I start this project since my undergraduate study. Under the guidance of Professor Wu, I conducted surveys and interviews. During my master's study, I deepened my study and finished this paper. I would also thank my parents, my friends, and my classmates for their help.

\section{Conflicts of Interest}

The author declares no conflicts of interest regarding the publication of this paper.

\section{References}

Arora, V., Caibc, Y., \& Jones, A. (2016). The National and International Impacts of Coal-to-Gas Switching in the Chinese Power Sector. Energy Economics, 60, 416-426. https://doi.org/10.1016/j.eneco.2016.07.026

Chang, Y., Huang, R., Ries, R. J., \& Masanet, E. (2015). Life-Cycle Comparison of Greenhouse Gas Emissions and Water Consumption for Coal and Shale Gas Fired Power Generation in China. Energy, 86, 335-343. https://doi.org/10.1016/j.energy.2015.04.034

Deng, D. S., \& Xu, F. (2012). The Current Policy Implementation Process of Community Health Education in China-Analysis Based on Smith Model. Journal of Wuhan University (Philosophy and Social Sciences Edition), 65, 5-12.

https://xueshu.baidu.com/usercenter/paper/show?paperid=2f9de6a2f2e863a27ddce917 66bc98b4\&site=xueshu_se

Hu, H., Yang, Q., Lu, X., Wang, W., Wang, S., \& Fan, M. (2010). Air Pollution and Control in Different Areas of China. Critical Reviews in Environmental Science and Tech nology, 40, 452-518. https://doi.org/10.1080/10643380802451946

Hu, Y., \& Zhang, J. (2013). China's Clean Energy Investment and Financing Dilemma and Outlet Research. Journal of Hebei University of Science and Technology (Social Science Edition), 13, 24-28. 
Huang, J. (2018). The Difficulties and Solutions to the Implementation of Agricultural Policies of Grassroots Governments under the Rural Revitalization Strategy-Based on the Analytical Perspective of Smith Model. Rural Economy, No. 11, 9-16.

Jiang, N. (2017). Restraining Factors and Path Choice of Policy Implementation in Campus Football in China-Under Smith' Policy-Implementation-Processing Framework. China Sport Science and Technology, No. 1, 3-8.

Li, Y. et al. (2020). Integrated Assessment of the Environmental and Economic Effects of "Coal-to-Gas Conversion" Project in Rural Areas of Northern China. Environmental Science and Pollution Research, 27, 14503-14514. https://doi.org/10.1007/s11356-020-08004-y

Lin, G. (1998). Energy Development and Environmental Constraints in China. Energy Policy, 26, 119-128. https://doi.org/10.1016/S0301-4215(97)00101-8

Minchener, A. J. (2011). Coal-to-Oil, Gas and Chemicals in China. London: IEA Clean Coal Centre.

https://usea.org/sites/default/files/022011_Coal-to-oil,\%20gas\%20and\%20chemicals\%2 0in\%20China_ccc181.pdf

Ning, S. (2011). Public Policy. Beijing: Higher Education Press. https://xueshu.baidu.com/usercenter/paper/show?paperid=47884b21dd2a90f4c2a8a5d $\underline{31 \mathrm{fd} 41 \mathrm{ec} 9 \& \operatorname{site}=\mathrm{xueshu} \text { se }}$

Qin, Y., Edwards, R., Tong, F., \& Mauzerall, D. L. (2017). Can Switching from Coal to Shale Gas Bring Net Carbon Reductions to China? Environmental Science \& Technology, 51, 2554-2562. https://doi.org/10.1021/acs.est.6b04072

Qin, Y., Tong, F., Yang, G., \& Mauzerall, D. L. (2018). Challenges of Using Natural Gas as a Carbon Mitigation Option in China. Energy Policy, 117, 457-462. https://doi.org/10.1016/j.enpol.2018.03.004

Ran, R. (2013). Political Incentives and Local Environmental Governance under the "Pressure System". Comparison of Economic and Social Systems, No. 3, 111-118. http://en.cnki.com.cn/Article_en/CJFDTotal-JJSH201303013.htm

Ren, X., Zeng, L., \& Zhou, D. (2004). Sustainable Energy Development and Climate Change in China. Climate Policy, 5, 185-198. https://doi.org/10.1080/14693062.2005.9685549

Schuldt, J. P., Yuan, Y. C., Song, Y., \& Liu, K. (2019). Beliefs about Whose Beliefs? Second-Order Beliefs and Support for China's Coal-to-Gas Policy. Journal of Environmental Psychology, 66, Article ID: 101367. https://doi.org/10.1016/j.jenvp.2019.101367

Smith, T. B. (1973). The Policy Implementation Process. Policy Sciences, 4, 197-209. https://doi.org/10.1007/BF01405732

State Council (2013). Notice on Printing and Dispatching the Action Plan for Air Pollution Prevention and Control. Beijing: State Council.

http://www.ramdevchemicals.com/p-notice-of-the-state-council-1430.html

The Oxford Institute for Energy Studies (2017). Searching for Natural Gas Demand in the Next Decade. Oxford Energy Forum, No. 110, 1-55. https://www.oxfordenergy.org/wpcms/wp-content/uploads/2017/09/OEF-110.pdf

Wang, J., Liu, X., Geng, X., Bentley, Y., Zhang, C., \& Yang, Y. (2019a). Water Footprint Assessment for Coal-to-Gas in China. Natural Resources Research, 28, 1447-1459. https://doi.org/10.1007/s11053-018-9446-8

Wang, W. (1998). An Analysis of Obstructive Factors in the Implementation of China's Housing Policy-An Explanation of Smith Model. Chinese Administrative Management, No. 12, 60-67. 
Wang, Z., Li, C., Cui, C., Liu, H., \& Cai, B. (2019b). Cleaner Heating Choices in Northern Rural China: Household Factors and the Dual Substitution Policy. Journal of Environmental Management, 249, Article ID: 109433.

https://doi.org/10.1016/j.jenvman.2019.109433

$\mathrm{Xu}, \mathrm{S}$., \& Ge, J. (2020). Sustainable Shifting from Coal to Gas in North China: An Analysis of Resident Satisfaction. Energy Policy, 138, Article ID: 111296. https://doi.org/10.1016/j.enpol.2020.111296

Zhu, T. (2015). Theoretical Thinking on Current Energy Transition in My Country. Guangming Daily, No. 12, 16.

https://xueshu.baidu.com/usercenter/paper/show?paperid=f5851e63b4fbeaa58db93771 8d4883cd\&site=xueshu_se

\section{Appendix: The Introduction of the Questionnaire}

A Survey on the Implementation of CTG Policies for Rural Residents in Qingzhou Town, Hebei Province

Questionnaire (the original version is written in Chinese since the respondents do not know English. This version is a translation one.)

Village

Dear Sir or Madam:

To gain first-hand resources of the implementation of CTG switching policies, I ask your help to finish this questionnaire. I hope you can provide true information to let the researcher know your opinion. The survey is anonymous and there is no right or wrong. The information obtained is only for research purposes and will not cause you any trouble. Please fill in the truth, thank you for your cooperation! 